\title{
ABO Mistyping of cis-AB Blood Group by the Automated Microplate Technique
}

\author{
Sejong Chun ${ }^{a} \quad$ Mi Ra Ryu $^{a} \quad$ Seung-Yeon Cha ${ }^{b}$ Ji-Young Seo ${ }^{a}$ Duck Cho $^{a, c}$ \\ ${ }^{a}$ Department of Laboratory Medicine and Genetics, Samsung Medical Center, Sungkyunkwan University School of Medicine, Seoul, \\ South Korea; \\ bSamsung Biomedical Research Institute, Samsung Medical Center, Sungkyunkwan University School of Medicine, Seoul, South Korea; \\ ${ }^{c}$ Stem Cell \& Regenerative Medicine Institute, Samsung Medical Center, Seoul, South Korea
}

\section{Keywords}

ABO $\cdot$ Mistyping $\cdot$ cis-AB $\cdot$ Automation .

Microplate technique

\section{Summary}

Background: The cis- $A B$ phenotype, although rare, is the relatively most frequent of $A B O$ subgroups in Koreans. To prevent $A B O$ mistyping of cis- $A B$ samples, our hospital has applied a combination of the manual tile method with automated devices. Herein, we report cases of ABO mistyping detected by the combination testing system. Methods: Cases that showed discrepant results by automated devices and the manual tile method were evaluated. These samples were also tested by the standard tube method. The automated devices used in this study were a OWALYS-3 and Galileo NEO. Exons 6 and 7 of the $A B O$ gene were sequenced. Results: 13 cases that had the cis- $A B$ allele showed results suggestive of the cis- $A B$ subgroup by manual methods, but were interpreted as $A B$ by either automated device. This happened in $87.5 \%$ of these cases by QWALYS-3 and $70.0 \%$ by Galileo NEO. Genotyping results showed that 12 cases were $A B O{ }^{*}$ cis$A B 01 / A B O^{*} 001$ or $A B O^{*}$ cis- $A B 01 / A B O^{*} 002$, and one case was $A B O{ }^{*}$ cis- $A B 01 / A B O{ }^{*} A 102$. Conclusion: Cis- $A B$ samples were mistyped as $A B$ by the automated microplate technique in some cases. We suggest that the manual tile method can be a simple supplemental test for the detection of the cis- $A B$ phenotype, especially in countries with relatively high cis-AB prevalence.

(c) 2018 S. Karger GmbH, Freiburg

Sejong Chun and Mi Ra Ryu contributed equally to this work.

\section{Introduction}

$\mathrm{ABO}$ blood group is known to be most important in blood transfusions; correct $\mathrm{ABO}$ grouping is the most important step of pre-transfusion testing to ensure safe transfusion to the patient. Considering its importance, manual tests can be of concern as they are prone to human errors. In addition, the labor-intensive nature of manual serologic tests is often considered a burden for efficient laboratory administration. Thus, clinical laboratories have been using automated systems to manage blood banks. Automated laboratory testing has several advantages, including increased quality of pre-analytical steps and reduced error rates [1]. Despite slow progress compared to that of the Western Hemisphere, automated systems for blood banks are beginning to be introduced in Korea.

It is expected that automation can be safe because of the use of bar-coded samples, lack of performance error during the analytical phase, and absence of errors in interpreting or reporting results during post-analytical phase [2]. However, we have observed some mistyping in cis-AB phenotype samples. Cis- $\mathrm{AB}$ is the most frequent among $\mathrm{ABO}$ subgroups in Korea, and, depending on the co-inherited $\mathrm{ABO}$ allele, phenotypes of cis- $\mathrm{AB}$ varies from typical $\mathrm{A}_{2} \mathrm{~B}_{3}$ (when paired with an $\mathrm{O}$ allele), $\mathrm{A}_{2} \mathrm{~B}$ (when paired with a $\mathrm{B}$ allele), and $A_{1} B_{3}$ (when paired with an $A$ allele) to atypical $A_{\text {int }} B_{3}$, $\mathrm{A}_{1} \mathrm{~B}_{\mathrm{m}}, \mathrm{A}_{1} \mathrm{~B}_{\mathrm{x}}$ [3]. Nine cis-AB alleles (cis-AB01, cis-AB01var, cis$\mathrm{AB} 02$ to $c i s-\mathrm{AB} 08$ ) have been reported so far [4], and correct $\mathrm{ABO}$ typing in individuals is of importance, as transfusion of $A B$ type blood to these patients can cause hemolytic adverse transfusion reactions [5-7]. To prevent $\mathrm{ABO}$ mistyping in cis-AB patients, our hospital has applied a combination of a manual tile method with automated devices. Herein, we share our experience with cis$\mathrm{AB}$ phenotype cases that automated devices failed to identify properly. 


\section{Material and Methods}

\section{Data Collection}

The cases of this study were seen at our hospital between April 2015 and May 2016. A total of 51,495 were tested for ABO typing. After introduction of the automated devices Galileo NEO (Immucor Gamma, Norcross, GA, USA) and QWALYS-3 (Diagast, Loos, France) at our institute, they were initially evaluated and then used routinely. The sera used for cell typing in QWALYS-3 were anti-A (9113D10 clone) and anti-B (9621A8 clone), and the Galileo NEO used anti-A (F98 7C6 clone) and anti-B (F84 3D6; F97 2 D6 clone).

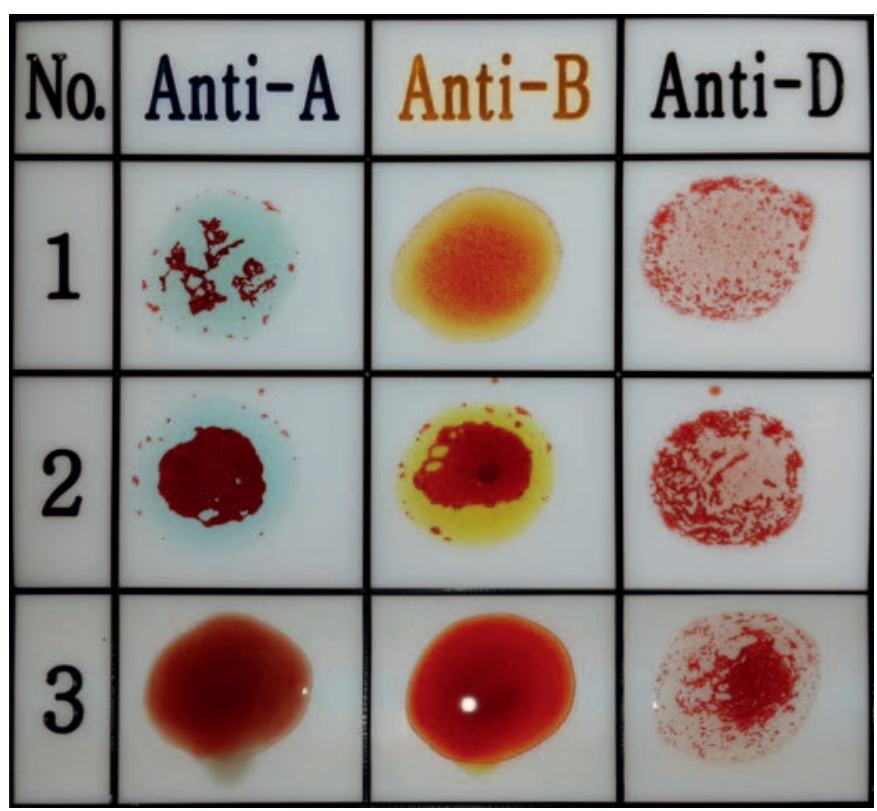

Fig. 1. Example of manual tile testing results of cell typing of (1) cis-AB, (2) typical $\mathrm{AB}$ and (3) $\mathrm{O}$ type blood. All samples were RhD-positive. Results for anti- $\mathrm{B}$ sera of $c i s-\mathrm{AB}$ represents weakly reactive, $\mathrm{AB}$ represents strongly reactive and $\mathrm{O}$ represents negative results.
Currently, all tests done by automated devices are duplicated by the manual tile method in our hospital. This involves mixing undiluted EDTA blood with anti-A (MH04 and A303 clone), anti-B (NB1.19, NB10.5A5 and NB10.3B4 clone), and anti-D (MAD2 clone) BioClone reagent (Ortho Clinical Diagnostics, Raritan, NJ, USA) on an acrylic tile plate. We have followed the manufacturer's instructions regarding the manual slide method with some modification. We omit the initial washing procedure and apply the test on an acrylic tile plate instead of slides. Reaction is interpreted with the naked eye. Examples of visual results of this method are presented in figure 1 . The manual tile method is done only on cell typing with anti-A and anti-B. Weak reaction to anti-A or anti-B was defined as weaker agglutination than normal RhD-positive-to-anti-D agglutination. Cases suggestive of a cis- $\mathrm{AB}$ phenotype by the manual tile method were selected.

We selected cases that were flagged by the automated device, or cases that showed discrepancy between manual and automated methods. Typical cases of discrepancy of automated and manual methods are observations suggestive of decreased reactivity to anti- $\mathrm{B}$ in the manual tile method compared to the automated device results or weak agglutination with B-cell RBCs in manual tube method. The outline of the work process during this period is presented in figure 2 .

\section{Evaluation of Suspected cis-AB Cases}

In cases that showed discrepant results by an automated device and the manual tile method, the manual tube method was applied to confirm ABO typing. Cases of interest were tested by both automated devices. In cases of the $A B$ blood type, forward typing with anti-A1 (anti-A1 lectin, Ortho Clinical Diagnostics) was additionally performed to confirm $\mathrm{A}_{2} \mathrm{~B}$ or $\mathrm{A}_{2} \mathrm{~B}_{3}$ phenotypes, which are typical cis-AB blood phenotypes in Korea [8-10]. Reagents used in serologic tests were as follows: forward typing was performed using Anti-A, Anti-B, and Anti-D BioClone reagent (Ortho Clinical Diagnostics) by both tile and tube method. Reverse typing was performed using Affirmagen A1 and B cells (Ortho Clinical Diagnostics) by the tube method.

\section{$A B O$ Genotyping}

DNA was extracted from each sample with the Qiagen DNeasy Kit (Qiagen, Hilden, Germany), and $\mathrm{ABO}$ exons 6 and 7, along with their flanking intron sequences, were amplified and sequenced in selected samples to confirm the cis$\mathrm{AB}$ blood grouping by previously described methods [10]. Sequences were ana-
Fig. 2. The outline of the work process to identify cis-AB samples with discrepancies between the automated and manual serological methods. ${ }^{*}$ Only cell typing was done with tile methods. ${ }^{* *}$ Anti-Al was applied to the manual tube method.

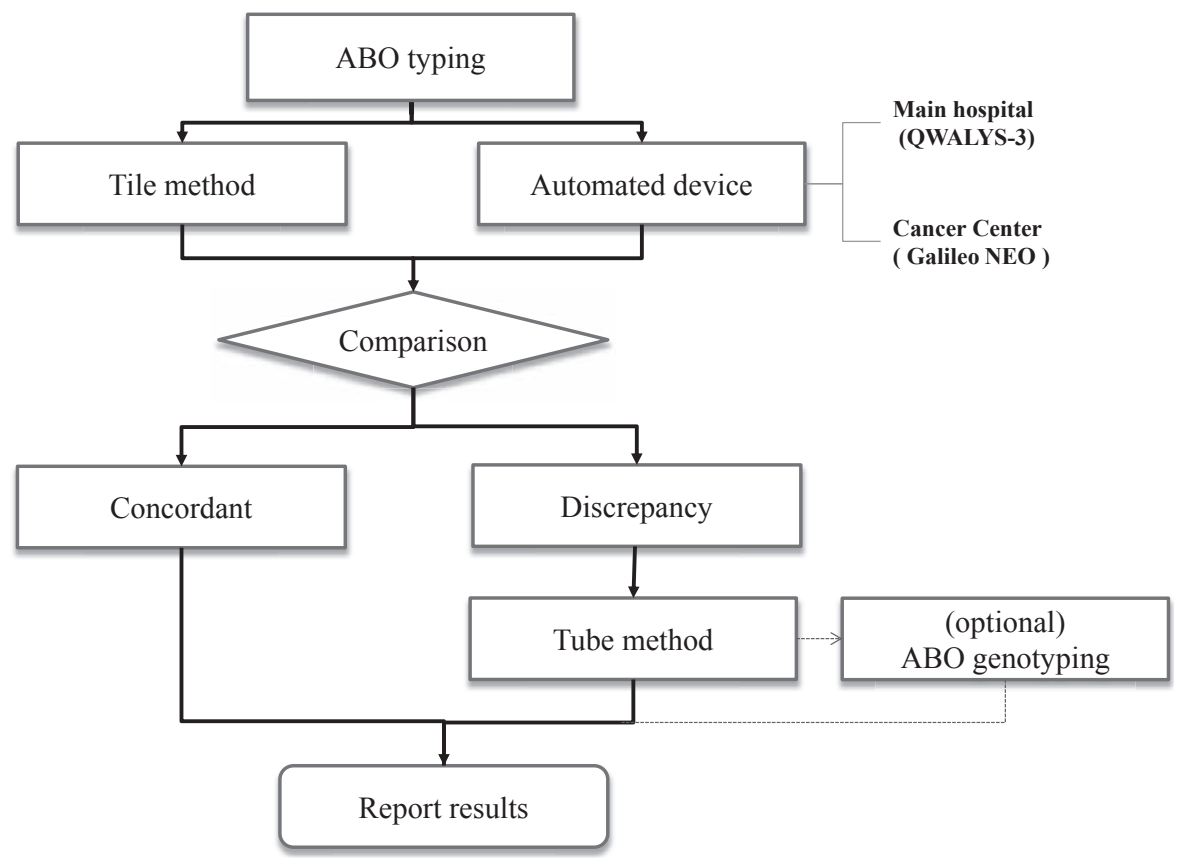




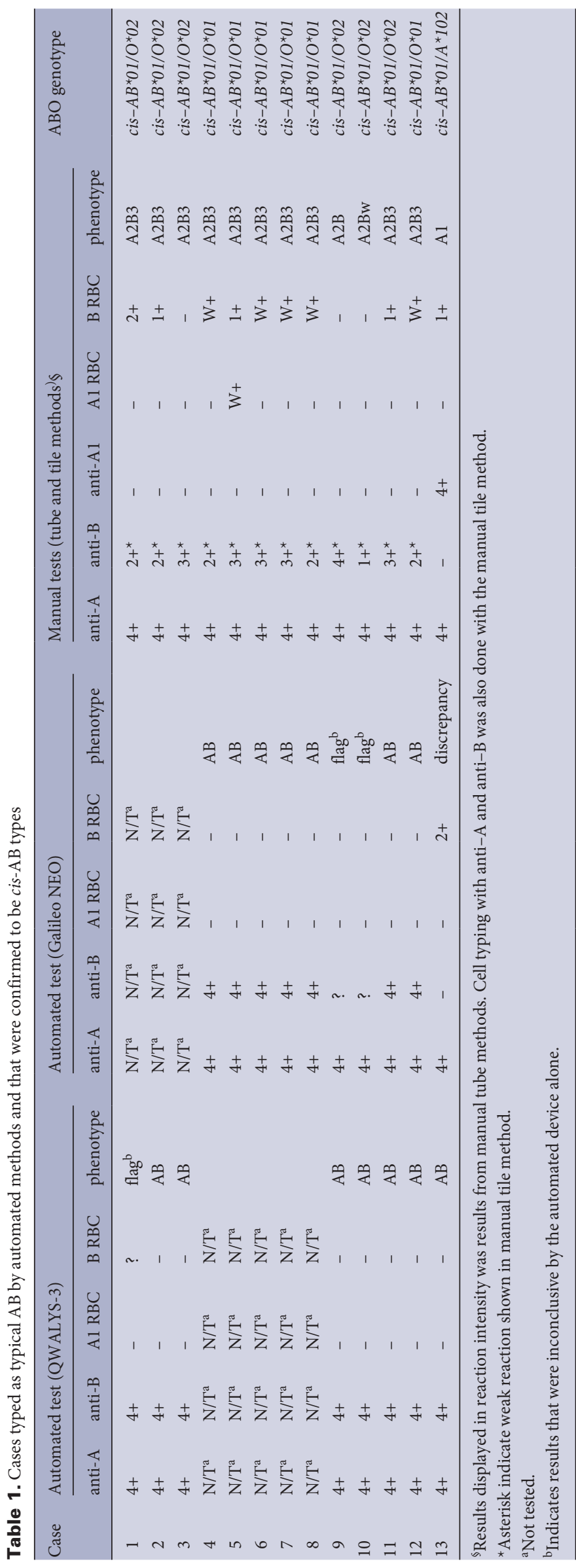

lyzed using Sequencher 5.0 (Gene Codes Corp, Ann Arbor, MI, USA) software. We referred to The Blood Group Antigen Gene Mutation Database (www.ncbi. nlm.nih.gov/gv/mhc/xslcgi.cgi?cmd = bgmut/home) for nomenclature of the detected cis-AB alleles [4].

\section{Results}

Discrepancies between the Automated and Manual Methods

We identified 13 cases of discrepancies between the automated and manual methods, as presented in table $1.87 .5 \%(7 / 8)$ of $c i s-\mathrm{AB}$ samples tested by QWALYS-3 were interpreted as AB type without any flag as an inconclusive $\mathrm{ABO}$ type, and $70.0 \%$ (7/10) of cis-AB samples were typed as AB by Galileo NEO. Overall, the manual methods showed decreased reactivity to anti-B sera in forward typing compared to that of the automated devices. QWALYS-3 and Galileo NEO flagged one case and two cases, respectively, as inconclusive $\mathrm{ABO}$ types, and each automated device interpreted $7 \mathrm{cis}-\mathrm{AB}$ cases as type $\mathrm{AB}$. These cases were revealed to be $A B O^{*}$ cis- $A B 01$ haplotype with $A B O^{\star} O 01$ or $A B O^{\star} O 02$. The overall frequency of cis- $\mathrm{AB}$ during this period was $0.025 \%$.

\section{A cis-AB Sample with Remarkable Discrepancy between QWALYS-3 and Others (Galileo NEO, Manual)}

We have observed 1 case of cis-AB with a pairing haplotype other than $\mathrm{O}$ allele. This was case 13 in table 1, with genotype of $A B O^{*}$ cis- $A B 01 / A B O^{*} A 102$. The QWALYS-3 device showed 4+ reactivity to anti-A sera and anti-B sera in cell typing, with no anti-A or anti-B in her serum, and the case was interpreted as an AB phenotype, while forward typing by Galileo NEO indicated 4+ reactivity to anti-A sera, but did not show reactivity to anti-B sera. Concurrent evaluation by the manual tile method showed similar results when compared with the Galileo NEO; the sample was further evaluated with manual tube testing which also showed a similar phenotype as the Galileo NEO. After transfusion with two packs of A+ leukocyte-reduced RBCs, QWALYS-3 testing showed an indeterminate result against anti-B sera, whereas results of other methods showed no change in anti- $\mathrm{B}$ reaction. Although the exact cause of the extra-reactivity to anti-B sera in cell typing remains unsolved, $\mathrm{ABO}$ mistyping as typical AB with QWALYS-3 was obvious, based on results prior to transfusion (table 2).

\section{Discussion}

This study illustrates the problems when automated devices are applied in a cis- $\mathrm{AB}$ phenotype-prevalent area. Although a rare subtype, cis-AB is encountered more frequently in Korea $[10,11]$ and Japan [8] than in other populations [12]. A Korean study reported a case of atypical delayed hemolytic transfusion reaction in a patient with cis-AB blood type following transfusion of Rh A-positive packed red blood cells and fresh frozen plasma [7]. Since the recommended blood for transfusion to cis- $\mathrm{AB}$ patients is type $\mathrm{O}$ red cells with type $A B$ platelets and $A B$ plasma, it is important to discriminate cis- $\mathrm{AB}$ from typical $\mathrm{AB}$ blood [5-7]. In addition to trans- 


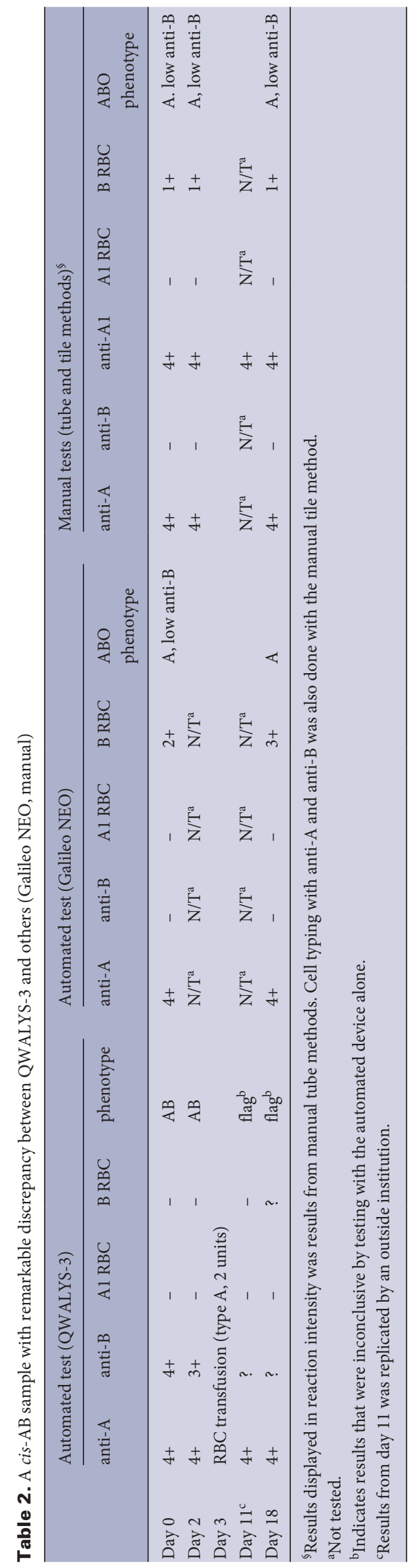

fusion concerns, there have been several paternity disputes in Korea and Japan because of an apparent contradiction to the general Mendelian inheritance of ABO blood groups [9, 10]. Correct $\mathrm{ABO}$ typing to the subgroup level is important in that matter, and, although sometimes challenging to novice personnel, serological testing can discriminate cis- $\mathrm{AB}$ [13-19], and other $\mathrm{ABO}$ subgroups $[20,21]$ using manual methods (table 3 ).

Our hospital encountered problems with QWALYS-3 in detecting cis- $\mathrm{AB}$ subtypes when initially evaluating the performance of this device [22]. QWALYS-3 interpreted multiple cases of cis-AB as typical AB; this was the initiation of this study. During our evaluation, we found that the Galileo NEO is subject to similar errors. We attempted to solve this problem by applying anti-A1 sera in cases of $\mathrm{AB}$ phenotype while forward typing with the tube method, and in cases with a negative reaction to anti-A1, we also performed $\mathrm{ABO}$ serum typing by the standard tube method, with a prolonged incubation time of $15 \mathrm{~min}$ at room temperature. We sought to ensure the detection of weak B-cell reaction in reverse typing.

Galileo NEO detects hemagglutination in microplates to determine the ABO blood type. This device has shown good results in $\mathrm{ABO}$ typing $[23,24]$, yet the cited studies found some discrepancies between results from this device and manual methods. Discrepancies were usually a result of weak reactions in manual testing; both studies indicated that this device is more sensitive in detecting agglutination reactions. The QWALYS system utilizes erythrocyte-magnetized technology [25], and its performance in $\mathrm{ABO}$ blood typing has been reviewed by many researchers. The QWALYS-2 device was examined by Schoenfeld et al. [26], who concluded that it was suitable for ABO grouping. Multiple Korean domestic studies reported that a later version of this device, QWALYS-3, showed good concordance with manual methods and determined that it could be used in routine pre-transfusion testing in the blood bank $[22,27,28]$. However, our institution previously reported that a cis-AB sample was ABO mistyped by QWALYS-3 [22]. Thereafter, to prevent $A B O$ mistyping, our hospital has applied a combination of testing by the manual tile method and examination with automated devices (fig. 2).

The cis-AB cases identified in this study show that both automated devices are more sensitive in forward typing than the manual methods but regarding reverse typing, QWALYS-3 and Galileo NEO showed inconsistent results. All of our cases were suspected to be $\mathrm{AB}$ subgroups with a cis- $\mathrm{AB}$ haplotype. We observed that Galileo NEO failed sporadically to detect reactions with B cells in reverse typing. Using a simple manual method, such as the tile method that was applied in this study, these shortcomings of the automated devices can be overcome. Whether or not there are inconsistencies regarding other $\mathrm{ABO}$ subgroups is unclear thus far; however, with the exception of cis-AB we did not detect any other systematically problematic phenotypes.

Case 13 in our study raised another interesting point. Although Galileo NEO and manual testing showed an A1 phenotype with low anti-B titer, this patient's red cells were typed as typical $A B$ type by QWALYS-3. The phenotype of this cis-AB sample might be A type with low titer of anti-B in her serum. The missing or very 
Table 3. Various reaction intensity of $\mathrm{A} / \mathrm{B}$ subgroups and cis-AB subgroups

\begin{tabular}{|c|c|c|c|c|c|c|c|c|}
\hline \multirow[t]{2}{*}{ Phenotypes } & \multicolumn{3}{|c|}{ Cell type } & \multicolumn{2}{|c|}{ Serum type } & \multirow[t]{2}{*}{ Genotypes } & \multicolumn{2}{|c|}{ Transfusion strategy based on phenotypes } \\
\hline & anti-A & anti-B & anti-A1 & A1 & B & & $\mathrm{RBC}$ & plasma/platelet \\
\hline$A_{1}$ & $4+$ & - & $4+$ & - & $4+$ & & A & A \\
\hline $\mathrm{A}_{2}$ & $4+$ & - & - & $-12+^{*}$ & $4+$ & & $\mathrm{A}$ or $\mathrm{O}$ & A \\
\hline $\mathrm{A}_{3}$ & $2+\mathrm{mf}$ & - & - & $-12+^{*}$ & $4+$ & & $\mathrm{A}$ or $\mathrm{O}$ & A \\
\hline B & - & $4+$ & - & $4+$ & - & & $\mathrm{B}$ & $\mathrm{B}$ \\
\hline $\mathrm{B}_{3}$ & - & $1+\mathrm{mf}$ & - & $4+$ & - & & $\mathrm{B}$ & $\mathrm{B}$ \\
\hline \multirow[t]{3}{*}{$\mathrm{A}_{2} \mathrm{~B}_{3}$} & $4+$ & $1+\sim 3+$ & - & - & $1+\sim 2+$ & \multirow{3}{*}{ cis- $A B 01 / O$} & A or $\mathrm{O}$ & $\mathrm{AB}$ \\
\hline & $4+$ & $1+\sim 3+$ & - & $1+$ & $1+$ & & $\mathrm{O}$ & $\mathrm{AB}$ \\
\hline & $4+$ & $1+\sim 3+$ & - & - & - & & $\mathrm{AB}$ or $\mathrm{O}$ & $\mathrm{AB}$ \\
\hline \multirow[t]{2}{*}{$\mathrm{A}_{1} \mathrm{~B}_{3}$} & $4+$ & $1+\sim 2+$ & $3+\sim 4+$ & - & $1+\sim 2+$ & \multirow[b]{2}{*}{ cis-AB01/A } & A or $\mathrm{O}$ & $\mathrm{AB}$ \\
\hline & $4+$ & $1+\sim 2+$ & $3+\sim 4+$ & - & - & & $\mathrm{AB}$ or $\mathrm{O}$ & $\mathrm{AB}$ \\
\hline \multirow[t]{2}{*}{$\mathrm{A}_{2} \mathrm{~B}$} & $4+$ & $4+$ & - & - & - & \multirow[b]{2}{*}{ cis- $A B 01 / B$} & $\mathrm{AB}$ or $\mathrm{O}$ & $\mathrm{AB}$ \\
\hline & $4+$ & $4+$ & - & $1+\sim 2+$ & - & & $\mathrm{B}$ or $\mathrm{O}$ & $\mathrm{AB}$ \\
\hline \multirow[t]{2}{*}{$\mathrm{A}_{1} \mathrm{Bw}^{* *}$} & $4+$ & $-/ \mathrm{W}+$ & $4+$ & - & $1+\sim 2+$ & \multirow[b]{2}{*}{ cis- $A B 01 / A$} & A or $\mathrm{O}$ & $\mathrm{AB}$ \\
\hline & $4+$ & $-/ \mathrm{W}+$ & $4+$ & - & - & & $\mathrm{AB}$ or $\mathrm{O}$ & $\mathrm{AB}$ \\
\hline \multicolumn{9}{|c|}{$\begin{array}{l}{ }^{*} \text { The occurrence of anti-A } 1 \text { is variable in these phenotypes. } \\
{ }^{*} A_{1} B_{e l}, A_{1} B_{x}, A_{1} B_{m} .\end{array}$} \\
\hline
\end{tabular}

low expression of the $\mathrm{B}$ antigen is in contrast with other typical cis$\mathrm{AB}$ subjects, and this can be due to allele competition in cases of cis- $\mathrm{AB} / \mathrm{O}$ genotypes. As the phenotype of a $A B O^{*} c i s-A B 01 /$ $A B O^{\star} A 102$ subject was previously observed as A1 phenotype multiple times, this lack of $\mathrm{B}$ antigen expression (phenotypically $\mathrm{A} 1$ ) is to be considered a not rare phenomenon in $A B O^{*}$ cis- $A B 01 /$ $A B O^{\star} A 102$ subjects [29-31]. This observation can be explained by the fact that the A1 glycosyltransferase is in competition with that from cis-AB01 and does not leave enough $\mathrm{H}$ substrate to produce detectable $\mathrm{B}$ antigen.

The present study summarizes our experience with $\mathrm{ABO}$ mistyping by automated microplate devices. All cases with $\mathrm{ABO}$ mistyping in our study had cis-AB haplotypes; thus, we suggest that automated microplate-based devices should be used with caution in cis- $\mathrm{AB}$-prevalent areas. Retesting automated device results of phenotypically $\mathrm{AB}$ subjects that show no reactivity to anti-A1 using the tile method is a suitable approach identify cis- $\mathrm{AB}$ cases and to avoid mismatched transfusions in these cases.

\section{Disclosure Statement}

The authors declare no conflicts of interest relevant to the publication of this article.

\section{References}

1 Shin KH, Kim HH, Chang CL, Lee EY: Economic and workflow analysis of a blood bank automated system. Ann Lab Med 2013;33:268-273.

2 Rathod K, Rathod J, Shah M, Gupta M, Soni SA, Shah SD, Shah MC, Bhatnagar NM, Gajjar MD: Switching over to fully automated for blood grouping - experience from a tertiary care teaching hospital blood bank. Pathol Lab Med 2013;5:37-39.

3 Cho D, Lee SY, Ryang DW: ABO subgroup studies in Korea. ISBT Sci Se 2015;10:332-335.

4 Patnaik SK, Helmberg W, Blumenfeld OO: BGMUT database of allelic variants of genes encoding human blood group antigens. Transfus Med Hemother 2014; 41:346-351.

5 Kang BJ: An anesthetic experience of a patient with cis A2B3 blood type. Korean J Anesthesiol 2001;40:95-99.

6 Kim DW: The problems in transfusion with cis $\mathrm{AB}$ type blood. Korean J Anesthesiol 1993;26:833-838.
7 Woo CM, Lee HJ, Kwak H, Shin SW, Kwon JY, Kim HK: Mismatched transfusion reaction in cis-AB: a case report. Korean J Anesthesiol 2006;51:632-637.

8 Yamaguchi H: A review of cis AB blood. Jinrui Idengaku Zasshi 1973;18:1-9.

9 Yoshida A: Genetic mechanism of blood group (ABO)expression. Acta Biol Med Ger 1981;40:927-941.

10 Cho D, Kim SH, Jeon MJ, Choi KL, Kee SJ, Shin MG, Shin JH, Suh SP, Yazer MH, Ryang DW: The serologi$\mathrm{cal}$ and genetic basis of the cis-AB blood group in Korea. Vox Sang 2004;87:41-43.

11 Cho D, Shin MG, Yazer MH, Kee SJ, Shin JH, Suh SP, Jeon MJ, Song JW, Ki CS, Ryang DW: The genetic and phenotypic basis of blood group A subtypes in Koreans. Transfus Med 2005;15:329-334.

12 Yazer MH, Olsson ML, Palcic MM: The cis-AB blood group phenotype: fundamental lessons in glycobiology. Transfus Med Rev 2006;20:207-217.
13 Lee SY, Phan MT, Shin DJ, Shin MG, Park JT, Shin JW, Yazer MH, Shin HB, Cho D: A novel cis-AB variant allele arising from a de novo nucleotide substitution c.796A>G (p.M266V) in the B glycosyltransferase gene. Transfus Med 2015;25:333-336.

14 Cai X, Jin S, Liu X, Fan L, Lu Q, Wang J, Shen W, Gong S, Qiu L, Xiang D: Molecular genetic analysis of ABO blood group variations reveals 29 novel ABO subgroup alleles. Transfusion 2013;53:2910-2916.

15 Mifsud NA, Watt JM, Condon JA, Haddad AP, Sparrow RL: A novel cis-AB variant allele arising from a nucleotide substitution A796C in the B transferase gene. Transfusion 2000;40:1276-1277.

16 Roubinet F, Janvier D, Blancher A: A novel cis AB allele derived from a $\mathrm{B}$ allele through a single point mutation. Transfusion 2002;42:239-246.

17 Tzeng CH, Chen YJ, Lyou JY, Chen PS, Liu HM, Hu HY, Lin JS, Yu LC: A novel cis-AB allele derived from a unique $796 \mathrm{C}>\mathrm{A}$ mutation in exon 7 of $A B O$ gene. Transfusion 2005;45:50-55. 
18 Liu YC, Ma L, Zhang DM, Zheng L, Liu Y, Wu MH, Xue M, Liang WB: The serological and genetic identification of a CisAB blood sample (in Chinese). Zhonghua Yi Xue Yi Chuan Xue Za Zhi 2011;28:552-554.

19 Yoon J, Youk HJ, Chang JH, Jang MA, Choi JH, Nam $\mathrm{MH}$, Choi JS, Lim CS: Identification of the $\mathrm{ABO}^{*}$ cisAB04 allele with a unique substitution C796A: the first case in Korea. Ann Lab Med 2016;36:620-622.

20 Fung M, Grossman BJ, Hillyer C, Westhoff CM: Technical Manual, 18th ed. Bethesda, American Association of Blood Banks, 2014.

21 Han KS, Park KU, Song EY: Transfusion Medicine, 4th ed. Seoul, Korea Medical Book Publisher, 2014.

22 Jang MA, Oh JW, Lee ST, Seo JY, Kim DW: Evaluation of the automated blood bank systems Galileo NEO and QWALYS-3 for ABO-RhD typing and antibody screening. Korean J Blood Transfus 2014;25:235-242.
23 Joo SY, Han KS, Kwak YK, Park KU: Evaluation of an Automated solid-phase cell adherence assay in the Galileo System (Immucor) for routine pretransfusion tests. Korean J Blood Transfus 2011;22:134-143.

24 Xu W, Wan F, Lou Y, Jin J, Mao W: Evaluation of an automated microplate technique in the Galileo system for $\mathrm{ABO}$ and $\mathrm{Rh}(\mathrm{D})$ blood grouping. Clin Lab 2014;60: 241-244.

25 Bouix O, Ferrera V, Delamaire M, Redersdorff JC, Roubinet F: Erythrocyte-magnetized technology: an original and innovative method for blood group serology. Transfusion 2008;48:1878-1885.

26 Schoenfeld H, Bulling K, von Heymann C, Neuner B, Kalus U, Kiesewetter H, Pruss A: Evaluation of immunohematologic routine methods using the new erythrocyte-magnetized technology on the QWALYS 2 system. Transfusion 2009;49:1347-1352.
27 An TK, Song YK, Seo HS, Kim KL, Kim JA, Ko CH, Lee DH, Kong SY: Evaluation of automated blood bank systems AutoVue Innova and QWALYS-3 for $\mathrm{ABO}-\mathrm{RhD}$ grouping and antibody screening. Korean J Blood Transfus 2012;23:204-209.

28 Koh YE, Yoon J, Kwon Sh, Kim YH, Choi JY, Kim JY, Cho CH, Lim CS, Yoon SY: Evaluation of the automated blood bank instrument QWALYS-3 for cross-matching tests. Korean J Blood Transfus 2014;25:218-225.

29 Cho D, Kee SJ, Shin JH, Suh SP, Ryang DW: Unusual phenotype of cis-AB. Vox Sang 2003;84:336-337.

30 Whang DH, Shin BM, Lee HS, Hur M, Han BY, Han $\mathrm{KS}$ : Unusual phenotype expression in a cis- $\mathrm{AB}$ trait: cis- $\mathrm{AB}$ child from a group $\mathrm{A}$ father and a group $\mathrm{O}$ mother. Korean J Blood Transfus 2000;11:169-175.

31 Kang SH, Lee YK, Park MJ, Shin DH, Cho HC, Lee $\mathrm{KM}$, Han KS: A Case of cis-AB without B antigen expression. Korean J Blood Transfus 2001;12:245-251. 